\title{
Say it with Images: Drawing on Jerome Frank's Ideas on Judicial Decision Making
}

\author{
Mateusz Stępień ${ }^{1}$
}

Published online: 17 January 2019

(C) The Author(s) 2019

\begin{abstract}
This paper aims to shed light on the putative functions of placing images in judicial opinions from the judges' perspective. Thus far, commentators have overlooked the functions that images play for judges when used in judicial opinions and consequently have failed to provide a thorough understanding of the process. To help fill this gap, Jerome Frank's ideas on judging will be presented. The argument goes that using images in judicial opinions can be interpreted as a way to enable the decisionmaking process to be, as far as possible, devoid of hypocrisy, closer to judicial candor and more open to scrutiny. This notion can be excavated from Frank's works in light of the existential features of both passing judgments and articulating decisionmaking processes by and for judges themselves. As will be shown, Frank's views on judicial decision-making are more original and enlightening than critics might suggest and they are particularly relevant when examining the use of images in judicial opinions from a judge's perspective.
\end{abstract}

Keywords Images in law · Judicial opinions · Jerome Frank · Decision-making process $\cdot$ Judging $\cdot$ Judicial hunch

Particularly in common law countries, there is a mild trend towards incorporating images within judicial opinions and, more generally, legal documents as a whole. Although there are no exact statistics of the numbers of court judgments in which images have been used, it is reasonable to speculate that the use of images is likely to increase in the future. Although authors working on the visualization of law interpret the use of images in judicial opinions as a prime example of a more general tendency towards a change in the template of law (from the text-based to imagebased) [e.g. 1, 21], their commentaries leave many fundamental questions unanswered. Consequently, there is a strong need for a more comprehensive and critical

Mateusz Stępień

mateusz.stepien@uj.edu.pl

1 Department of Sociology of Law, Faculty of Law and Administration, Jagiellonian University, Bracka Street, 12, 31-007 Cracow, Poland 
understanding of both the actual and the desirable roles that images play in judicial opinions.

This paper aims to shed light on the functions of placing images in judicial opinions from the judges' perspective. Thus far, commentators have overlooked the functions that images play for judges when used in judicial opinions and consequently have failed to provide a thorough understanding of the process. To help fill this gap, I draw on Jerome Frank's ideas on judging in order to show that using images in judicial opinions can be interpreted as a way to enable the decision-making process to be, as far as possible, devoid of hypocrisy, closer to judicial candor and more open to scrutiny. This notion can be excavated from Frank's works in light of the existential features of both passing judgments and articulating decision-making processes by and for judges themselves. As will be shown, Frank's views on judicial decision-making are more original and enlightening than critics might suggest and they are particularly relevant when examining the use of images in judicial opinions from a judge's perspective.

The discussion proceeds in three parts. In the first section, I review the up-to-date literature on the use of images in judicial opinions in order to extract the most dominant threads of thought and to highlight the deficiencies in the way that these issues have been conceptualized and approached so far. The second section is devoted to the legal thoughts of Jerome Frank that are relevant to the practice of inserting images into legal documents. In this respect, Frank's essay entitled Say it with Music [6, see also 7: 165-189], which is devoted to the existential dimension of justifying decisions, is especially revealing. His thoughts on the judicial decision-making process and judicial opinions seem very contemporary and in tune with modern legal practice. As such, they can provide the necessary tools to fill an important gap in the literature regarding the use of images in court documents. The final section contains some basic conclusions about the most important lessons learned from Frank's contribution. The overall aim of the paper is to open up new perspectives for a more complete understanding of the roles that images currently play in justification and the roles that they could have in the future.

\section{Dominant Threads in Literature}

Although there are an increasing number of studies on images in judicial opinions [e.g. $2,3,9,10,15,16,18,19]$ and on related, but mostly more general issues $[1,5,12$, $17,18,20-22]$, the subject matter still remains outside of the mainstream of legal academia. Nevertheless, the recent scholarship provides a useful tool for reconstructing the dominant ways in which the practice has been conceptualized. It also helps us to better understand what is missing in the current literature. From all the works analyzed, four main approaches emerged.

\subsection{Benefits and Harms Approach}

Authors taking this approach commonly discuss the advantages and disadvantages (benefits and harm) of inserting images into judgments to ascertain the evaluative 
character of the process. For example, Dellinger, a pioneer in studying non-textual elements in judicial opinions, highlights the "special dangers" of using visual material in the attachments to judicial opinions [3: 1707]. Porter directly "analyzes risks and benefits of images in... judicial opinions" [19: 1698], and comments more generally on the "risks of visual advocacy" [19: 1752]. She says that if visual argument remains unregulated it threatens the "fundamental premises of legal discourse and decision-making" [19: 1694]. In a similar vein, Marder examines "the benefits and harms of the justices' use of images in their opinions" [15: 357]. From a more general perspective, Sherwin characterizes so-called "pictorial turn" in legal context as "a source of new opportunities as well as new dangers" [21: 119]. What is important to note here is that virtually all the authors stress the negative aspects of using images in judicial opinions. This is so striking that Goodrich rightly notes that the general literature on the subject "is to date largely cautionary and exhortative" [9: 3 , $11]$.

Most of the authors fail to reveal their assumptions on how legal decisions are passed and on what functions judicial opinions fulfill, nor do they give any indications of their visions for future practice. But, without first establishing a contextual framework, the "benefits and harms approach" seems to be seriously flawed. Any estimation of consequences of using images in judicial opinions presented by a given author cannot be fully apprehended and scrutinized if we don't know their more basic thoughts about the legal decision-making process. Discussions on the advantages and disadvantages of a particular practice should contain a solid elaboration on the standards or criteria adopted by the commenting author. It's not good enough to make vague references to standards without explicating exactly what these standards are.

An example of this kind of incompleteness can be found in Porter, when she warns us that, if visual argument stays unregulated, it threatens the "fundamental premises of legal discourse and decision-making" [19: 1694]. It could be assumed that these "fundamental premises" work as evaluative standards. Unfortunately, exactly what these standards are remains a mystery. The actual set of premises used would obviously have a major bearing on the attitude towards inserting images into judicial opinions.

Johansen and Robbins give general advice on whether or not to use "visuals as legal reasoning" [12]. To this end, they point out three criteria: "enhancing the reader's comprehension of the analysis", "the document's overall design" and "meeting professional norms". Only after addressing all three should lawyers, which includes judges, decide whether or not to include "visuals" in their documents. Notice that only the first criterion has strong evaluative potential. According to Johansen and Robbins, the main (or even the only) rationale for using visuals in a legal context is to enhance the reader's understanding of the document. Note that this leaves aside any discussions of any other putative functions of using images in judicial opinions. The second and third points ("document's overall design" and "meeting the professional norms") are not only indisputable when formulated in such an abstract way, but also they also appear trivial and superficial.

Starting from much broader perspective, Feigenson and Spiesel ask the question: "are digital images good for law?" [5: 196]. When addressing the "advantages and 
disadvantages for legal judgments", they list five normative criteria of "good and just decision making": they have to be accurate; based on good thinking; reached in fair process; have an expressive value; and lead to desirable outcomes. Although those criteria are vague and to some extent overlapping, such an approach is undoubtedly more sophisticated and considered when compared to the earlier examples. What should be stressed, and what is typical in the literature as a whole, is that all the criteria mentioned are "external". They are not related to the decision makers' inner processes nor to the consequences of decisions on the judges themselves. Standards of "good and just decision making" proposed by Feigenson and Spiesel not only lack any references to judge-related issues, but they also completely neglect to tell us what they think the desirable features of judicial opinions are.

\subsection{Visual Persuasion}

Authors using this approach tend to view images in judicial opinions as an instance of a much broader trend towards using non-textual elements in legal documents in order to further rhetorical and argumentative aims. The "visual persuasion" approach dominates the recent literature. For instance, Dellinger writes on "visual argumentation" [3: 1705], pointing out the role of images in "supporting the argument". Porter frequently uses phrases such as: "image-driven advocacy", "new digital advocacy", "visual argument", "visual persuasion", "visual tools of persuasion", and "visual advocacy" [19]. Johansen and Robbins dwell on "visual persuasion" [12] and Murray elaborates on the general category of "visual legal rhetoric" $[17,18]$.

When viewed through that lens, judges who insert image into their opinions are seen as intentional agents trying to use the best available tools for persuading their audiences. Images are a fragment of the judges' (and more generally lawyers') rhetorical toolkit. From this instrumental perspective, images are just new tools for argumentation (in some cases, as Murray notes, the "sharpest" ones). Such an approach is based on underlying assumptions about both the ontology of images and the reasons why judges might choose to use them in their opinions. This "persuasion" framework also determines the evaluative criteria employed when considering the "benefits and harms" of such practice. To be sure, the power to influence an audience is a very important function, maybe even the most important, but it's not the only legitimate reason for judges to use images in their opinions. Consequently, such a reduction is not desirable if the aim is to get a comprehensive view of the process (a view supported by Goodrich [9: 39]). As a final point, because the visualization of law takes place at the end of the decision-making process, authors claim that images are directed to future audiences, so giving further weight to their persuasive role. This appears to ignore the possibility that images may be used to help to articulate what happened earlier.

\subsection{Accommodation Approach}

From this perspective, the use of images in judicial opinions is an instance of a more general cultural process that is changing the character of law in the "digital 
baroque" period [21]. Expansion of new media, armed with sophisticated technology, will sooner or later lead to the so-called "visualization" of law. This process can be described as employing images in such a way as to make law more closely reflect changes in society as a whole. To put it another way, according to the "accommodation approach", law ought to catch up with the reality of contemporary life and, with respect to judicial opinions, this can be achieved by changing the dominant text-centered mode of presentation in favor of a multimedia approach.

For example, Katsh, undoubtedly a pioneer of this way of thinking, writes about "ongoing pressures from the computer for law to accommodate itself to the visual and to employ new means to communicate" [13: 145]. Porter stresses the "irresistible force of these cultural and technological upheavals" [19: 1721] and Boehme-Neßler frames the practice of inserting pictures into judicial opinions as an instance of the inevitable process of making law more and more based on "visual communication" [1]. Author of the seminal Pictorial Law, BoehmeNeßler often gets close to the claim of technological determinism when he notes that "law will find it difficult to hold this hard line [i.e. being in opposition to visualization] in the future" [1: ix]. In a very similar way, Margolis stresses that "incorporating images and videos" into judicial opinions "is an inevitable part of the change brought by digital writing and reading" [14: 25]. Even Sherwin, an author known for his subtle and humanistic approach, asks, "how does visual culture alter the legal mind" [21: 3]. Thus, the assumption is that new cultural phenomena have already influenced the legal field. What is more striking, is that visual-based culture is treated as something external to be differentiated from traditional "word-based law". What is more puzzling is that Sherwin asks "what constitutes prudent judgment in predominantly visual society?" [21: 6], rather than taking a less deterministic approach by questioning how prudent judgment could be reached in predominantly visual society. The general assumption here is that prudent judgment has been somehow changed due to technological developments. Sherwin tries to establish a virtual jurisprudence that would be "more suitable to the actual conditions of contemporary life" [21: 5]. So, according to Sherwin, both the practice of law and the way we theorize about it needs to be readjusted to fit to the digital world we live in.

The accommodation thesis brings with it the risk of conflating the descriptive dimension (the world is changing in a certain way) with the normative one (law must catch up with the reality of contemporary life). The conclusion that because the world is in some way changing the legal sphere needs to change in a similar way is problematic. It leaves aside the question of the justified distinctiveness of law from an axiological and teleological perspective. Moreover, it frames the practice of using images in judicial opinions merely as a process associated with keeping up with a general trend in society. This approach falsely assumes a fundamental disconnection between law and culture and, furthermore, places culture as the driving force behind legal practice. As a consequence, the important nuances and particularities associated with the "visualization of law", which are discussed later, are ignored. 


\subsection{The Fetishization of Images}

Regardless of whether the incorporation of images into judicial opinions is portrayed as a distinct practice or an example of more general tendencies within legal practice as a whole, images are most commonly conceptualized as a separate category, distinct from text. Understood in this way, they can then be explained and assessed en bloc. This tendency to homogenize images as single category and treat them as an unified group with shared features is termed the "fetishization of images". Within such a view, images and text are separate symbolic modes that follow their own rules, one being autonomous from, or even in opposition to, the other. Using general quantifiers (which encompass large sets of designators) makes the whole set of items within each category easy to comprehend and provides ready-to-use general labels. This dichotomous mode of thinking, in which images oppose text, infiltrates the entire scholarship. Feigenson and Spiesel neatly summarize this dominant approach: "Law, like most other disciplines or practices that aspire to rationality, has tended to identify rationality (and hence its virtue) with texts rather than pictures" [5: 4]. Other authors express this attitude in a direct way. For instance, the power of images is described by Tushnet as "irrational" [22: 694] in contrast to text, which gives "an opportunity for explication and reflection" [3: 1704]. Images are referred as "entities that work more quickly and convey information intuitively" [19: 1752-1754] and "much more immediately and tightly linked with emotion than text is" [22: 2012: 691; 9: 35].

Especially when looking from the functional perspective, images do not form a homogeneous category. Even if we take a particular type of image, such as photographs, they function differently in various situations [see 4]. What is striking, is that, when used in specific way, images can a play very similar role to a typical text-based communication. For example, maps and photos are commonly used to enhance the clarity and transparency of the narrative. Of course, some images can facilitate almost instant communication, while others encourage reflection and deeper scrutiny. Although it is freely admitted that images can hasten communication, bestow emotional potency, and help to simplify complex issues, in most actual instances, the use of images in judicial opinions results in more complex communications that require more time from the interpreter to reflect on the nuances. Overall, the literature places too much emphasis on the emotional qualities associated with using images in judicial opinions and tends to ignore their pragmatic and more subtle uses.

At one extreme, images can have definitive prescribed sets of meanings and so operate in a similar way to the literal use of words. An example of this is the American DOT pictogram system used for traffic signs. Conversely, an abstract painting has no set meaning and any interpretation is subjective. In practice, most images, particularly within a legal context, fall somewhere in between and require a lesser or greater degree of interpretation. This is also true of text. Put oversimply, words can be read as labels denoting actual things in the world, they can instruct, convey meaning through symbolism, or, in the case of some experimental poetry, be totally abstract. It's not without a reason, that Horace in his Ars Poetica shows us the similarities between poetry and pictures (ut pictura poesis). 
As Horace explains, "As is painting, so is poetry: some pieces will strike you more if you stand near, and some if you are at a greater distance: one loves the dark; another, not afraid of the critic's subtle judgment, chooses to be seen in the light; one may please once whilst the other will give pleasure if ten times repeated" (translation by Christopher Smart). When linked in a certain way with text, images can be characterized as, using Jerome Frank's categories, "sober", "objective", or "precise". In different settings, images can be "quite thin" or "ephemeral". However, in all cases they form a part of the larger communicative framework. Rather than sticking to the dichotomous way of thinking about images and text, it's more realistic to assume that text and images interrelate with each other.

Furthermore, the relationships between images and text can vary greatly according to the character and context of each specific case. Where images are used, it is of crucial importance how they are mixed with textual elements, whether they are supplemented with additional textual comments, and whether the particular judge has a previous history of using them. In most well-known cases of using images in judicial opinions, judges have almost always tightly linked "the visuals"-often in a very direct way - to their textual comments and analysis. In these cases, images and words work hand-in-hand in forming the meanings. So the reflection on intersections between images and text in judicial opinion needs to be developed as a starting point instead of fetishizing images. If we take for example the famous opinion by Judge Posner (Gonzalez-Servin v. Ford Motor Company, 662 F.3d 931 [7th Cir. 2011]), where he included a photograph of an ostrich with its head in the sand next to a photograph of a man in a suit with his buried in the sand, it is only by reading the text that you understand that the mythical behavior attributed to ostriches was being used as a metaphor for the appellate lawyer's failure to observe precedents in the case.

What is obvious is that nobody looks only at just the images in judicial opinions. Court rulings are not like TV or billboard advertisements that we can view semifocused. Knowing the context in which particular images are used is vital for their interpretation. For instance, how differently would a judicial opinion be interpreted if it were known that the author frequently used non-orthodox elements within legal documents as a personal stamp. Instead of holding onto the "fetishization of images approach", the interpreter must assess how images relate to the text, taking each case on its own merit.

Summing up, none of the four dominant approaches adopted by scholars is completely inaccurate or totally invalid. The problem is that they present judicial practice as more flat and homogeneous than it really is. Although there is an important rationale behind the "benefits and harms approach", authors need to frame this within their understanding and expectations of judicial practice. Authors that focus on "visual persuasion" tend to blind themselves to other plausible reasons why images are used in judicial opinions. The "accommodation" framework maintains that the use of images is as a result of pressure to catch up with society as a whole. Not only are the premises unsubstantiated but such a view undermines the positive and proactive approaches to using images in legal documents. "Fetishization of images" leads to a gross simplification of the 
understanding of how images work and ignores the relationships between images and text that play a vital role in interpretation.

As stated above, using images in judicial opinions can be comprehensively evaluated only against an assumed descriptive and normative vision of the decision-making process. Different choices in this respect inevitably determine the approach toward the practice of inserting images by judges.

\section{Frank on Judicial Opinions}

One of the reasons why Frank's legal thoughts have not been utilized for the study of court opinions to date is most likely because of the superficial readings of his ideas as an attempt to incorporate aspects of Freud's psychological theories into the legal sphere. In this respect, Horwitz rightly takes a quite different track than most commentators, describing Frank's book Law and the Modern Mind as embodying an "existentialist" strand of Legal Realism [11: 176-177]. Although Horwitz does not develop this idea further, it can be noted that Frank claims that there are existential conditions of legal decision-making that are not dependent on institutional or organizational factors. At this point, it is useful to note that, at the beginning of his career, Frank worked as a successful corporate lawyer, then served as a high-level federal public official, and ultimately became a distinguished federal appellate judge [8, 23]. He had first-hand experience relating to judging and writing judicial opinions.

Many commentators acknowledge that Frank stresses the ongoing effects of subjectivity during decision-making processes and, as a consequence, the uncertainties inherent in judging. Frank takes this further by pinpointing a set of deeper, more crucial determinants in the judging process. The most important of these are:

1. The fundamental role of the hunch in judicial decision-making. This does not mean that the decision-making process is either irrational or lacks any inherent control mechanisms. The decision-maker will most often try to evaluate initial hunches by employing legal rules and juristic methods, so in effect, re-working the case material.

2. The impossibility of eliminating emotions from the judging process, whether negative or positive. For Frank, emotions are an essential part of the legal decision-making process at the descriptive level, though their evaluation is a separate matter.

3. The non-linear character of the actual judicial decision-making process, in contrast to the linearity of decisions suggested by the official narrative.

4. The uniqueness of each decisional situation, including the decision-makers' mindset.

5. The complex and dynamic character of the inner experiences of a judge (which are idiosyncratic) and their crucial role in the processes of reaching decisions.

6. The inevitable separateness of decision-maker from the external world and even from his previous experiences. 
According to Frank, judicial decisions are reached in a quite different way than traditional theories assumed. To better capture how judicial decisions are made, Frank refers to the concept of gestalt [6: 928], the "wholeness" of both the judge's experiences during case that influence the decision-making process and the judge's response toward the case. What is crucial here is that the gestalt-like characteristic of judging, "the non-analytical character of the decisional process" [6: 928], impacts other aspects of the decisional process and the judicial opinions. One of the most far reaching consequences is the existence of inherent and unavoidable problems with the articulation of decisional premises ("real reasons"). As Frank states, a judge "experiences a gestalt; that is why he has difficulty in reporting his experiences analytically" [6: 929]. This produces problems with internal communication, "inside the judge," and, no matter how awkward it may seem, between the judge and the judges' opinions. These findings are rarely acknowledged in the prevailing literature, but, for Frank, the fundamental difficulty of judges in articulating their reasoning at the end of a case cannot be eliminated completely. It is important to note that Frank is an adherent of a judicial candor and a strong critic of hypocrisy in legal decision making. This helps explain why he was strongly committed to reporting the problems of of reporting what actually happens during the decision-making process at the justification stage.

So why, according to Frank, does the gestalt-like character of judging lead to serious troubles with articulating decisional premises? Put simply, the idiosyncratic and gestalt-like experiences of a judge cannot be reduced to simple propositional theses without loosing something important. This is the main reason why decision makers have a fundamental difficulty in articulating these experiences, even for themselves. Frank uses the term of "inexpressibility of the decisional process" to highlight the problems with formulating what really happens when passing a decision in a "logical, lingual form". Judges' responses are partly based on and bounded by their "<wordless knowledge>" [6: 932]. Meanings that lay beyond the discursive form cannot, without distortion, be conveyed in words. There is always a part of the decisional premises that is "unspeakable" and so cannot be written down. The above is true in relation to particular feelings, emotions, and hunches, but relates most especially to the holistic-type experiences, which consist of many smaller elements, some of which are impossible to put labels on. To some degree, any attempt to place such an element into a "logical verbal form must distort it" [6: 933].

According to Frank, the decisional processes of judges have some similarities with "the artistic process", namely the act of discovery, the inevitability of creativity, and the strong impact of personality. What is crucial here for Frank, is that judges' decisional experiences, like those of an artist, cannot be repeated. They happen only once. This unrepeatability influences the final shape of a particular judicial opinion, which, according to Frank, is to some degree, always unauthentic, formulated on a slippery basis, and based on premises that are distant from what really happened. But for Frank the use of non-orthodox tools by judges can reduce these dysfunctional states.

Before we get to those judicial candor-enhancing devices, it's worth noting that when Frank stresses the inherent limitations of writing as a tool that is unable to capture the judges' gestalt experience, he relies mainly on Susanne Langer's comments 
on language and her criticism of logical positivism [6: 939]. Langer emphasizes the linear and successive character of words, limitations of written communication that "sets bounds to the complexity of speakable ideas", rendering certain ideas "too subtle for speech". This explains failures of writing to comprehend certain ideas contained within emotions and memories. As a kind of remedy she introduces the possibility of "wordless symbolism". Echoing Langer's views, Frank sees these same "inherent weaknesses of language" [6: 931] relating to the preparation of judicial opinions.

Against such background, we should understand Frank's essay Say It With Music as a direct call to judges to acknowledge the inherent weakness of words. Say it with music is the title of an Irving Berlin song that was very popular in the 1940's. The lyrics indicate that love is a complex, internal state that cannot be communicated easily and accurately with words. Frank uses this analogy to emphasize the importance of non-verbal elements. According to Berlin's song, we should make use of music when we want to express our feelings. When speaking about love it always appears that something has been left out, usually the parts that are most vivid, crucial, subtle, moving and transforming. To Frank, at a deeper level and only to some extent, a judge faces similar existential troubles while articulating the reasons of an already reached decision. The suggestion is that, although there is a significant quantitative difference between a lover and a judge, judges should follow the example of the lover from Berlin's song and try to "say it with music".

By "music", Frank is obviously referring to finding alternative ways to express experiences that are difficult to accurately capture in words. Music, for example, allows for a more nuanced expression of emotional thoughts, but there are other tools that could be used, most notably images. Say It With Music is an invitation for judges to use "new forms to symbolize feelings" [6: 931] in order to express the actual decisional premises in a more authentic way (primarily for themselves). Frank realized that this was a somewhat idealistic notion. Even armed with "musical tools" (which have their own limitations), judges would never be in a position to be able to fully articulate all premises of their decisions; the ways they report their cases will never be completely adequate and transparent for themselves and others [6: 933]. However, Frank does not see this as a reason not to try and he encourages legal decision makers to make this process as sincere, transparent and open to scrutiny as possible by criticizing the dominant, "purist" template of judicial opinions [see e.g. 20]. The gestalt-like experiences of judges require new tools of expression which work in gestalt-like fashion, enabling the reader to take them all in at once.

Frank's approach may sound radical but it is consistent with his general view on law and legal decision-making and of the myth-making processes of both. Author of Law and Modern Mind, Frank believes that encouraging authenticity (judicial candor) could bring about fundamental changes to how law works. Looking from the perspective of rational critique of the decision, the gap between actual reasons for decisions and their official justifications bring multiple dysfunctions, especially when considered in a long run. Moreover, according to the transmission model of communication, information that is yet to be well established and crystallized can be transmitted via different mediums. So what would be changed if we were to assume that a large part of the judging process could not be articulated discursively and, 
to some degree, even stays beyond the consciousness of the decision-maker? In this case there is no analytically differentiated quanta of information waiting to be "transmitted". This opens up the possibility of a new function for inserting images into judicial opinions. Frank's elaborations show that using images is not limited to reasons or justification, but it could also help judges express what actually happens when passing decisions in a more meaningful and accurate way. Thus, images can be seen also as tools for self-expression, or even self-discovery, for judges, by fulfilling the following putative functions: (1) a way of expressing the decision-makers' gestalt, (2) as an individualization device that help judges to express their idiosyncrasies in a meaningful and relevant way, (3) as a tool to help decision makers explore the phenomenology of their own legal judgments. The message for future authors on the visualization of law is that is vital to understand the judge's role in the decision-making process when commenting on the function of images in judicial opinions.

\section{Summary: Filling the Gap}

Frank's ideas offer new light on the use images in judicial opinions. These are the most basic conclusions:

(1) Images can fulfill a variety of functions when used in judicial opinions. Any assessment of this practice always rests, whether the auditor is aware of it or not, on an initial assumption about judicial decision-making and judicial opinions at both the descriptive and the normative level. For example, if one treats the articulation of legitimate reasons for the judgment as more important than an adequate reporting of the course of the decision-making process, he would most likely accept inserting the images, but only when they are used to enhance the clarity of presented reasons. On the other hand, when the reporting is seen as more important, different usages of images in judicial opinions would be acknowledged as both functional and legitimate. From a different angle, believing that both the form and content of judicial opinions should be more in tune with cultural and technological changes implies more open and positive attitudes toward using images in judicial decisions. Generally, commentators who are strongly attached to the orthodox vision of legal opinions would not be so open and receptive to the project of making them more sound to the popular culture. Notice that a few instances of inserting images into judicial opinions can be fairly interpreted as an attempt to make judicial opinions more in tune with the dominant culture (see the Grayson v. Schuler case [666 F.3d 664 \{7th Cir. 2012\}], where the judge inserted the photo of Bob Marley in order to show how dreadlocks look like).

(2) Current scholarship limits the potential functions of images in judicial opinions to exclude functions that relate specifically to the authors of those opinions. As we have seen, this is mostly as a result of the dominance of the "visual persuasion" approach in recent literature. As Frank teaches, elaborations on visual communication should also embrace the internal communication of the decision maker and its relation with final product. The power of images has to be recognized also for the decision makers themselves. Thus, images can help to facilitate the tensions or 
internal communications that occur between a decision maker's thoughts at a certain point in time, his earlier recollections during the decision-making process, and the final published decision. Frank opens the window for issues related to the "communication of judges with their own opinions". In this sense images have an invaluable potential to enable communication in ways that words cannot do, both for the author and interpreter. Consider the dissent opinion of judge Damon J. Keith in the Northeast Ohio Coalition v. Husted (837 F.3d 612 [6th Cir. 2016]) case regarding the constitutionality of the State of Ohio amendment to the voting laws. Judge Keith expressed strong emotional reaction to the majority decision upholding laws under scrutiny, which — according to Keith—de facto restricts the voting rights (especially for minorities) and violates the Constitution ("I am deeply saddened and distraught by the court's deliberate decision to reverse the progress of history. I dissent"). Second, the Judge tried to put the whole issue in the larger context of struggles for equal voting rights in the US. Without avoiding emotionally charged tone, he declared: "I will not forget. I cannot forget-indeed America cannot forget—-the pain, suffering, and sorrow of those who died for equal protection and for this precious right to vote". Then judge Keith included thirty-seven pictures of persons killed while struggling for voting rights in the fifties and sixties. Using their pictures (supplemented with their short bios) could be interpreted as a tool which enabled the judge to express his emotional state. The pictures used in such way create, as Goodrich stated in references to another opinion with images, "momentary window onto the Judge's motives, a glimpse of intent and desire" [9: 38].

(3) Images can play a role in fostering judicial authenticity and candor. Although images are often interpreted only as tools for making certain meanings easier to apprehend, they should also be considered as devices that enhance the authenticity of judicial opinions. This is a highly complicated issue because the candor could be understood differently and as such is a multi-level phenomenon. For example, Richard Posner is the judge who quite often (especially in comparison with the average judge) uses images in his opinions (see e.g. Sandifer v. US Steel Corp. 678 F.3d 590 [7th Cir. 2012]; Conrad v. AM Community Credit Union 750 F.3d 634 [7th Cir. 2014]). His strong tendency to insert the images, most likely photos, can be seen as his deliberatly employed style of writing of judicial opinions. This is a very specific type of judicial candor, often omitted in the literature, indicating that opinions are being prepared in a way that manifests the author's vision of the desirable way of their both form and content. As a part of being faithful to his own writing style, Posner sometimes inserts the images into the main body of the opinion [see 20].

(4) Looking from Frank's perspective, some cases of using images in judicial opinions should be interpreted as instances of trying to "say it with music". Probably the most important lesson from reading Frank in this context is the reconceptualization of the practice of inserting images into judicial opinions. Rather than being conceptualized in the text-vs-pictures framework, it should be interpreted on a background of "pure" and "impure" styles of writing the judicial opinions. This implies that some cases of using the images should be understood as a way of searching for modes of expressions, "new forms to symbolize feelings" [6: 931]. In this light, some instances of inserting images into judicial opinions should be put in the line with certain textual attempts, such as using poetic tools, but also diagrams and 
charts making the narrative simpler, more creative, innovation-searching. It breaks down the differentiation between textual and non-textual elements of opinions and suggests the new one-the dichotomy between the scholastic and petrified style of writing versus the innovation-searching style that looks for new ways of expressing the meanings.

As an illustration, let us consider the judge Fred Biery's opinion in the case 35 Bar and Grille LLC. v. The City of San Antonio, 943 F2d 706 (2013). It concerns the imposition of new clothing requirements by the City of San Antonio on the strip clubs. The whole tone of the opinion is based on an intended language ambiguities. Moreover, the opinion includes a paraphrase of the Bible and other works of literature, such as Hamlet and To Kill a Mockingbird. The overall tone of the main part of the opinion could be characterized as cryptic, allusive, associational, and even humorous. It is also because the judge inserted the picture of the local dancer-Miss Wiggles, who, what is important, hasn't been in any direct way related to the case. The photo shows Miss Wiggles, an exotic artist, completely dressed, spinning on head on the swivel chair. This photo works hand in hand with the text, they both complement each other to produce the overall effect. Also the photo of Miss Wiggles could be read as a metaphor directing the reader toward the registers of meaning that lie beyond the expressed reason-giving. It is a hidden argument for the regulation of the nudity in San Antonio's strip clubs. As Goodrich noted in reference to 35 Bar and Grille LLC case, "this use of image is essential to a proper understanding of the judgment, to the reconstruction of its motivation and to apprehension of its scope" [9: 38].

(5) What is inherent in Frank's writings, but missing in the dominant literature, is the difference between visualization of thought, a process oriented toward a future audience, and cases where the thought encapsulated through images is a process of reflecting on the past by the decision maker.

By analyzing the gaps in the current literature and drawing on the ideas expressed by Frank in his essay Say It With Music, it has been possible to highlight the importance of understanding the judicial decision-making process and the role of the judge when considering how images function within judicial opinions-an aspect so far ignored by contemporary scholars. The findings of this paper do not claim to reshape the whole way of thinking about images in judicial opinions, but rather they open a new territory for consideration. Hopefully, this will encourage future authors to question the dominant approaches in the current literature and allow room for a more nuanced way of using images in judicial opinions.

Acknowledgements I wish to express my sincere gratitude to Professor Neal Feigenson, for his helpful suggestions and comments on the first draft of the paper.

OpenAccess This article is distributed under the terms of the Creative Commons Attribution 4.0 International License (http://creativecommons.org/licenses/by/4.0/), which permits unrestricted use, distribution, and reproduction in any medium, provided you give appropriate credit to the original author(s) and the source, provide a link to the Creative Commons license, and indicate if changes were made. 


\section{References}

1. Boehme-Neßler, Volker. 2011. Pictorial Law: Modern Law and the Power of Pictures. Berlin: Springer.

2. Davies, Ross E. 2012. Marshall's Maps, the U.S. Reports, and the New Judicial Restraint. Green Bag 2d 15(4): 445-462.

3. Dellinger, Hampton. 1997. Words are Enough: The Troublesome Use of Photographs, Maps, and Other Images in Supreme Court Opinion. Harvard Law Review 110(8): 1704-1753.

4. Dudek, Michał. 2018. A Few Questions Concerning Photographs in Court Decisions. Archiwum Filozofii Prawa i Filozofii Spotecznej 2: 60-74.

5. Feigenson, Neal, and Christina Spiesel. 2009. Law on Display: The Digital Transformation of Legal Persuasion and Judgment. New York: New York University Press.

6. Frank, Jerome. 1948. Say it with Music. Harvard Law Journal 61: 921-957.

7. Frank, Jerome. 1949. Courts on Trial. Myth and Reality in American Justice. Princeton: Princeton University Press.

8. Glennon, Robert J. 1985. The Iconoclast as Reformer, Jerome Frank's Impact on American Law. Ithaca: Cornell University Press.

9. Goodrich, Peter. 2017. Imago Decidendi: On the Common Law of Images. Leiden: Brill.

10. Goodrich, P. 2017. Pictures as Precedents. The Visual Turn and the Status of Figures in Judgments. In New Directions in Law and Literature, ed. Elizabeth S. Anker and Bernadette Meyler, 176-192. New York: Oxford University Press.

11. Horwitz, Morton J. 1992. The Transformation of American Law, 1870-1960: The Crisis of Legal Orthodoxy. New York: Oxford University Press.

12. Johansen, Steven J., and Ruth Anne Robbins. 2015. Art-Iculating the Analysis: Systemizing the Decision to Use Visuals as Legal Reasoning. Journal of the Legal Writing Institute 20: 57-108.

13. Katsh, Ethan M. 1995. Law in a Digital World. New York: Oxford University Press.

14. Margolis, Ellie. 2015. Is the Medium the Message? Unleashing the Power of E-Communication in the Twenty-First Century. Legal Communication \& Rhetoric: JALWD 12: 1-28.

15. Marder, Nancy S. 2013. The Court and the Visual: Images and Artifacts in U.S. Supreme Court Opinions. 88 Chicago-Kent Law Review 88(2): 321-364.

16. Mnookin, Jennifer L. 1998. The Image of Truth: Photographic Evidence and the Power of Analogy. Yale Journal of Law \& the Humanities 10(1): 1-74.

17. Murray, Michael D. 2015. The Ethics of Visual Legal Rhetoric. Legal Communication \& Rhetoric: JALWD 13: 107-155.

18. Murray, Michael D. 2019. The Sharpest Tool in the Toolbox: Visual Legal Rhetoric. Journal of Legal Education (forhcoming).

19. Porter, Elizabeth. 2014. Taking Images Seriously. Columbia Law Review 114(7): 1687-1782.

20. Posner, Richard A. 2013. Judicial Opinions and Appellate Advocacy in Federal Courts: One Judge's Views. Duquesne Law Review 51: 3-39.

21. Sherwin, Richard K. 2011. Visualizing Law in the Age of the Digital Baroque: Arabesques and Entanglements. London: Routledge.

22. Tushnet, Rebecca. 2012. Worth a Thousand Words: The Images of Copyright Law. Harvard Law Review 125: 683-759.

23. Volkomer, Walter E. 1970. The Passionate Liberal: The Political and Legal Ideas of Jerome Frank. The Hague: Nijhoff.

Publisher's Note Springer Nature remains neutral with regard to jurisdictional claims in published maps and institutional affiliations. 